\title{
Changes in Membrane Lipid Composition of Clostridium acetobutylicum during Acetone-Butanol Fermentation: Effects of Solvents, Growth Temperature and $\mathrm{pH}$
}

\author{
By C. LEPAGE, F. FAYOLLE, M. HERMANN AND \\ J.-P. VANDECASTEELE* \\ Direction de Recherche Biotechnologie et Environnement, Institut Français du Pétrole, \\ 1 et 4, avenue de Bois-Préau, 92506 Rueil-Malmaison Cédex, France
}

(Received 11 March 1986; revised 24 July 1986)

\begin{abstract}
Changes in membrane lipid composition of Clostridium acetobutylicum were studied during acetone-butanol fermentation. Large changes were found in phospholipid composition and in fatty acid composition, the latter characterized mainly by a decrease in the unsaturated/saturated fatty acid $(\mathrm{U} / \mathrm{S})$ ratio. The effects of the addition of alcohols (ethanol, butanol, hexanol and octanol) and of acetone were also studied. In all cases, large changes were observed in the U/S ratio but with differences which were related to the chain lengths of the alcohols. The effect of solvents appears to account for a large part of the changes in lipid composition observed during the fermentation. The $\mathrm{pH}$ was also important, a decrease in $\mathrm{pH}$ resulting in a decrease in the $\mathrm{U} / \mathrm{S}$ ratio and in an increase in cyclopropane fatty acids. The effect of increasing temperature was mainly to increase fatty acid chain lengths.
\end{abstract}

\section{INTRODUCTION}

It is generally accepted that the limitation at about $16-20 \mathrm{~g} \mathrm{l}^{-1}$ in total solvent concentration observed in acetone-butanol fermentation is due to the toxicity of the butanol produced (Moreira et al., 1981). This end product can affect a variety of target sites in cells leading to growth inhibition. Although the exact mechanism by which alcohols inhibit bacterial growth is not known, they have been shown to affect the membrane physiology of many micro-organisms by partitioning in lipid bilayers and then interfering with lipid-lipid and lipid-protein interactions (Jain \& Wu, 1977; Jain et al., 1978). These effects are largely interpreted in terms of membrane viscosity which is decreased by the presence of alcohols (Ingram, 1976; VollherbstSchneck et al., 1984).

In the present work we studied the variations in lipid composition of membranes of Clostridium acetobutylicum during acetone-butanol fermentation, with the aim of correlating the variation observed with the effects of the solvents produced. We thus examined the effects on membrane fatty acid composition of acetone and the alcohols ethanol, hexanol, octanol and butanol. The effect of $\mathrm{pH}$, an important parameter in acetone-butanol fermentation, was also studied. Because of the well documented effect of growth temperature on membrane lipid composition (Khuller \& Goldfine, 1974; Russell, 1984) we also examined the response of $C$. acetobutylicum to different temperatures.

\section{METHODS}

Microbiological methods. C. acetobutylicum (IFP 903; ATCC 39057) was grown under strict anaerobiosis, using an anaerobic glove box (Lacalhene, France) and a gassing manifold as described by Balch et al. (1979). The culture

Abbreviations: CL, cardiolipin; PG, phosphatidylglycerol; PE, phosphatidylethanolamine; $N$-PE, $N$ monomethylphosphatidylethanolamine; PX, unidentified phospholipid; U/S ratio, unsaturated/saturated fatty acid ratio. 
medium contained $\left(1^{-1}\right): 30$ or $60 \mathrm{~g}$ glucose $4 \mathrm{~g}$ yeast extract (Difco) $; 2.5 \mathrm{~g} \mathrm{CH}_{3} \mathrm{COOH} ; 0.5 \mathrm{~g} \mathrm{KH}_{2} \mathrm{PO}_{4} ; 0.1 \mathrm{~g}$ $\mathrm{MgSO}_{4} \cdot 7 \mathrm{H}_{2} \mathrm{O} ; 10 \mathrm{mg} \mathrm{FeSO}{ }_{4} \cdot 7 \mathrm{H}_{2} \mathrm{O} ; 10 \mathrm{mg} \mathrm{MnSO}{ }_{4} \cdot \mathrm{H}_{2} \mathrm{O}$. The pH was adjusted to 6.0 by addition of ammonia.

Minimum inhibitory concentration (MIC), defined as the highest concentration of a given solvent allowing measurable growth, was determined in $18 \times 150 \mathrm{~mm}$ tubes containing $5 \mathrm{ml}$ of medium with $30 \mathrm{~g}$ glucose $\mathrm{l}^{-1}$. The tubes were inoculated with $5 \%(\mathrm{v} / \mathrm{v})$ of a $16 \mathrm{~h}$ culture grown on the same medium and incubated at $35^{\circ} \mathrm{C}$ under static conditions. Growth was estimated by measurement of $\mathrm{OD}_{600}$ over a period of $24 \mathrm{~h}$.

Lipid analyses were made on bacteria grown in fermenters. Two successive preculture steps before inoculation of the fermenters were used. A flask containing $10 \mathrm{ml}$ of medium with $30 \mathrm{~g}$ glucose $1^{-1}$ was incubated at $35^{\circ} \mathrm{C}$ overnight, and used to inoculate a flask containing $200 \mathrm{ml}$ of the same medium. This flask was used, after about $6 \mathrm{~h}$ incubation at $35^{\circ} \mathrm{C}$, to inoculate a fermenter (Biolafitte) containing 41 (final vol.) of medium containing $60 \mathrm{~g}$ glucose $1^{-1}$. The fermenter contents were incubated at $35^{\circ} \mathrm{C}$ with slow stirring; the pH was regulated at 6.0 by addition of $6 \mathrm{M}$-ammonia. Gas production was measured continuously using a gas counter (Flonic) equipped with a recording device. Samples were taken for measurements of growth $\left(\mathrm{OD}_{600}\right)$, glucose (enzymic analysis with the Beckman Analyser 2), solvents and acids, the latter being measured by gas chromatography (GC). A $3.2 \mathrm{~mm} \times$ $2 \mathrm{~m}$ column containing $15 \%$ free fatty acid phase (FFAP) on $80 / 100$ Chromosorb WAW, operated at $90{ }^{\circ} \mathrm{C}$ was used for solvents; for acids a $3.2 \mathrm{~mm} \times 2 \mathrm{~m}$ column packed with $25 \%$ (w/w) neoglycopolyacid (NGPA) on $100 / 120$ Chromosorb WAW, operated at $135^{\circ} \mathrm{C}$, was used. Four samples of cells were taken at various times for analysis of lipid composition. For the study of the effects of the presence of solvents and of the action of $\mathrm{pH}$ and temperature the same general fermentation conditions were used but the final fermentation volume was 1.81. Also, an additional transfer step was done : $200 \mathrm{ml}$ portions of the culture growing in the fermenter were used after about $5 \mathrm{~h}\left(\mathrm{OD}_{600}\right.$ about 4$)$ to inoculate other fermenters prepared as described above, each having the parameter in question (alcohol concentration, temperature or regulated $\mathrm{pH}$ ) set at the required value. After $5 \mathrm{~h}$ of growth in these conditions, the bacteria were harvested for lipid analysis.

Lipid analysis. Cells were harvested by centrifugation $\left(20 \mathrm{~min}, 48000 \mathrm{~g}, 0{ }^{\circ} \mathrm{C}\right)$. Pellets were washed twice with distilled water and stored at $-20^{\circ} \mathrm{C}$. Lipids were extracted by a modification of the method of Bligh \& Dyer (1959) using a single extraction operation with a solvent/cell paste ratio of $60: 1(\mathrm{v} / \mathrm{w})$, as recommended by Nelson (1975). The lipids were purified from non-lipid contaminants by extraction with $0.74 \% \mathrm{KCl}$ as described by Folch $e t$ al. (1957). The proportions of methanol, chloroform and water in the total mixture at the moment of phase partition were respectively 2,2 and 0.95 (by vol.). Lipid extracts were finally dissolved in $\mathrm{N}_{2}$-flushed chloroform/methanol $(2: 1, \mathrm{v} / \mathrm{v})$ mixtures to $1 \%(\mathrm{w} / \mathrm{v})$ final concentrations. They were stored at $-20^{\circ} \mathrm{C}$.

Thin-layer chromatography (TLC) on silica gel plates with a $4 \mathrm{~cm}$ concentration zone (Merck 13794) was used to separate the different lipid classes. Phospholipids were first separated from neutral lipids by migration in acetone (Gentner et al., 1981), and were separated further into phospholipid classes by migration in chloroform/methanol/acetic acid $(13: 5: 2$, by vol.) in the same dimension. The two-dimensional technique described by Herrero $e t$ al. (1982) was also used. The detection reagents used were iodine vapour and the spray reagents (Sigma) molybdenum blue, orcinol (Bial's reagent) and ninhydrin. Lipid phosphorus was determined by the method of Rouser et al. (1970). Plasmalogen analyses were made on the separated phospholipids by the method of Viswanathan et al. (1968).

Fatty acid methyl esters were prepared by transesterification of the extracts with $0.5 \mathrm{M}$-sodium methoxide (Alltech) by the method of Pelick \& Mahadeyan (1975). Transesterification with $14 \%(\mathrm{w} / \mathrm{v}) \mathrm{BF}_{3} / \mathrm{methanol}$, as described by Morrison \& Smith (1964), was used to prepare fatty acid methyl esters and dimethylacetals from plasmalogens. These two classes of constituents were then separated by TLC on silica gel G plates (Merck 11845) by two successive migration steps in toluene; the corresponding spots were scraped off and eluted for further analyses. The fatty acid and aldehyde composition of individual phospholipid classes was determined according to Nelson (1975).

The quantitative analysis of fatty acid methyl esters was done by GC using a Packard 438 apparatus with flame ionization detection. A $3 \mathrm{~m} \times 3.2 \mathrm{~mm}$ column packed with $15 \%(\mathrm{w} / \mathrm{w})$ diethylene glycol succinate on $80 / 100$ Chromosorb WHP was used; it was operated at $170{ }^{\circ} \mathrm{C}$ with $\mathrm{N}_{2}$ as carrier gas. Chromatograms were recorded and analysed with a Packard 604 integrator. For identification purposes, fatty acid esters and dimethylacetals were also analysed by GC coupled with mass spectrometry (MS) on a Kratos MS 80 with the same GC conditions.

\section{RESULTS}

\section{Characterization of membrane lipids}

Acetone-butanol fermentation usually represents the first stage of growth and acid production followed by the second stage where solvents are produced with partial re-utilization of the acids (Walton \& Martin, 1979). This pattern is illustrated in Fig. 1 for cell samples taken at various stages of the fermentation. The $\mathrm{pH}$ was maintained at 6.0 by ammonia addition during 


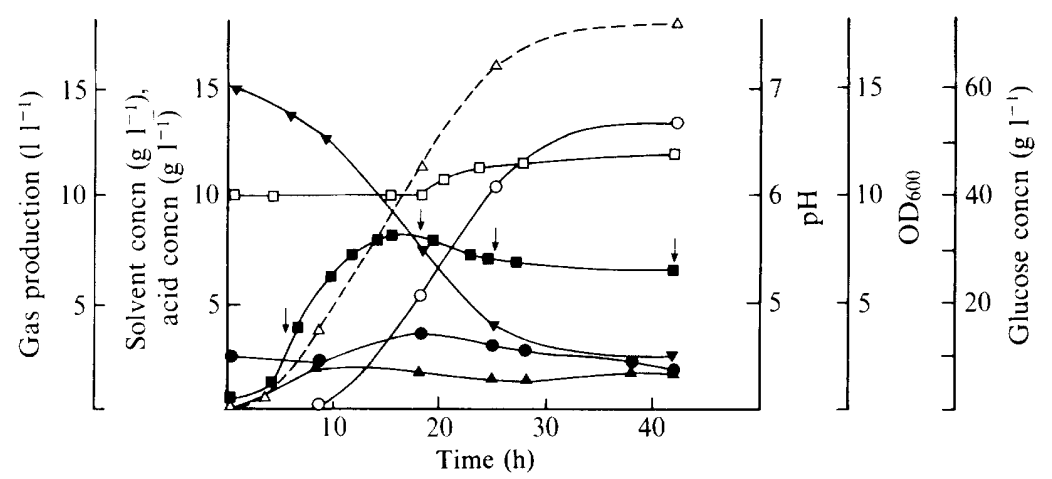

Fig. 1. Acetone-butanol fermentation by C. acetobutylicum 903 . Culture conditions are indicated in Methods. $\square, \mathrm{OD}_{600} ; \nabla$, glucose concn; $\triangle$, gas production; $O$, solvent concn; $O$, acetic acid concn; $\mathbf{A}$, butyric acid concn; $\square, \mathrm{pH}$. Vertical arrows indicate the times when samples of the culture were harvested for study of the lipid composition of the bacteria.

growth and acid production but increased to $6 \cdot 3$ during solvent production because of acid consumption.

Total lipids accounted for $1-1.5 \%(\mathrm{w} / \mathrm{w})$ of the wet cell wt $(5-6 \%, \mathrm{w} / \mathrm{w}$, of the dry cell wt). Spectrophotometric examination $(200-800 \mathrm{~nm})$ did not reveal the presence of pigments in the lipid extracts dissolved in methanol.

After separation by TLC in one dimension, six lipid spots containing phosphorus, as revealed by the molybdenum blue reagent, were detected. Two other spots were revealed with general lipid reagents, but not by the glycolipid-specific orcinol reagent. No further identification was attempted on these two spots. With our two-dimensional technique of lipid separation, we could still separate only six spots corresponding to phospholipids.

The phospholipids were tentatively identified, by migration with their respective standards, as phosphatidic acid (traces), cardiolipin (CL), phosphatidylglycerol (PG), phosphatidylethanolamine (PE), $N$-monomethylphosphatidylethanolamine $(N$-PE) and an unidentified phospholipid (PX) which, like PE and $N$-PE, was ninhydrin-positive. The results for the fractions PE and $N$-PE are given together, under the name PE, as the sum of the two fractions, as the two compounds were not always completely resolved. Analysis of the plasmalogen composition of the phospholipids showed that the PX fraction was only in plasmalogen form as it gave, after acidic hydrolysis, a single spot which migrated exactly like lyso-PE.

Fatty acids were analysed using the basic transesterification technique which is specific for esterified fatty acids. Ten fatty acids, 12:0, 14:0,14:1, 16:0,16:1, 17 $\triangle\left(\mathrm{C}_{17}\right.$ cyclopropane $)$, $18: 0,18: 1,18: 2$ and $19 \triangle$ were identified both by comparison of retention times with those of standard samples in GC and by GC/MS. The alk-l-enyl chains of plasmalogens were identified after acidic transesterification and contained the same carbon chains as fatty acids, except for the absence of $\mathrm{C}_{12: 0}$ and $\mathrm{C}_{18: 2}$.

The possible presence of hopanoids in the membrane lipids of $C$. acetobutylicum was also investigated in collaboration with Professor M. Rohmer (ENSCM, Mulhouse, France). Neither bacterial triterpenes such as diplotene, diplopterol and squalene nor bacteriohopanes were detected.

\section{Lipid variation during acetone-butanol fermentation}

The results obtained are summarized in Tables 1 and 2. Regarding phospholipids (Table 1), $P E$ and $P G$ decreased during the fermentation whereas $C L$ and $P X$ increased; the ratio of acidic to neutral phospholipids $(\mathrm{CL}+\mathrm{PG}) /(\mathrm{PE}+\mathrm{PX})$ increased slightly. Although ten different fatty acids were identified (Table 2), three of them, 16:0,16:1 and 18:1, accounted for $90 \%$ of the total. Two cyclopropane fatty acids $(17 \triangle$ and $19 \triangle)$, which originate respectively from the $16: 1$ and 18:1 fatty acids, were also present. During solvent production, saturated and cyclopropane fatty acids increased, whereas unsaturated fatty acids decreased. These changes took place for the most part early in solvent production whereas phospholipid changes were more gradual. 
Table 1. Membrane phospholipid composition of C. acetobutylicum during acetone-butanol fermentation

The results are means of at least three experiments \pm SD.

\begin{tabular}{|c|c|c|c|c|}
\hline \multirow{2}{*}{$\begin{array}{c}\text { Solvents } \\
\left(\mathrm{g} \mathrm{l}^{-1}\right)\end{array}$} & \multicolumn{4}{|c|}{ Phospholipids* } \\
\hline & $\mathrm{CL}$ & PG & $\mathrm{PE}$ & $\mathrm{PX} \dagger$ \\
\hline 0 & $15 \pm 0.7$ & $29 \cdot 1 \pm 1 \cdot 4$ & $46.2 \pm 1.8$ & $9.5 \pm 0.9$ \\
\hline $6.3 \pm 0.3$ & $26.5 \pm 0.6$ & $18.3 \pm 0.7$ & $40 \cdot 8 \pm 2$ & $14.3 \pm 1 \cdot 1$ \\
\hline $9.6 \pm 0.6$ & $38.7 \pm 1.5$ & $11 \cdot 1 \pm 1$ & $36 \pm 1 \cdot 3$ & $14.3 \pm 0.9$ \\
\hline $13.5 \pm 0.5$ & $39 \pm 1.5$ & $8.5 \pm 1.5$ & $34 \pm 1.6$ & $18 \cdot 2 \pm 2 \cdot 1$ \\
\hline
\end{tabular}

* Expressed as a percentage of the total phosphorus of phospholipids. $\dagger$ Unknown phospholipid (see text).

Table 2. Membrane fatty acid composition of C. acetobutylicum during acetone-butanol fermentation

The results are means of at least three experiments \pm SD.

\begin{tabular}{|c|c|c|c|c|c|}
\hline \multirow{2}{*}{$\begin{array}{c}\text { Solvents } \\
\left(\mathrm{g} \mathrm{l}^{-1}\right)\end{array}$} & \multicolumn{5}{|c|}{ Fatty acids* } \\
\hline & $12: 0$ & $14: 0$ & $14: 1$ & $16: 0$ & $16: 1$ \\
\hline 0 & $0 \cdot 4 \pm 0.05$ & $3 \cdot 5 \pm 0 \cdot 1$ & $0.5 \pm 0.08$ & $45 \cdot 2 \pm 0 \cdot 8$ & $31.8 \pm 0.7$ \\
\hline $6.3 \pm 0.3$ & $0.8 \pm 0.1$ & $4.6 \pm 0.2$ & $0.4 \pm 0.05$ & $48 \cdot 8 \pm 1$ & $19.2 \pm 0.6$ \\
\hline $9.6 \pm 0.5$ & $0.9 \pm 0.05$ & $5 \pm 0.5$ & $0.3 \pm 0.05$ & $49.8 \pm 1.1$ & $17.1 \pm 0.8$ \\
\hline $13.5 \pm 0.5$ & $1.2 \pm 0.2$ & $5.2 \pm 0.4$ & $0.3 \pm 0.1$ & $49 \cdot 5 \pm 1$ & $17.3 \pm 0.8$ \\
\hline
\end{tabular}

\begin{tabular}{|c|c|c|c|c|c|c|}
\hline \multirow{2}{*}{$\begin{array}{c}\text { Solvents } \\
\left(\mathrm{g} \mathrm{l}^{-1}\right)\end{array}$} & \multicolumn{5}{|c|}{ Fatty acids* } & \multirow[b]{2}{*}{$\mathrm{U} / \mathrm{S} \dagger$} \\
\hline & $17 \triangle$ & $18: 0$ & $18: 1$ & $18: 2$ & $19 \triangle$ & \\
\hline 0 & $2 \pm 0.2$ & $1 \pm 0 \cdot 1$ & $13.5 \pm 0.4$ & $0.4 \pm 0.05$ & $1 \cdot 1 \pm 0.2$ & 0.98 \\
\hline $6.3 \pm 0.3$ & $10 \cdot 4 \pm 1 \cdot 2$ & $1.9 \pm 0.3$ & $6.7 \pm 1.5$ & $0.7 \pm 0.3$ & $6.1 \pm 0.6$ & 0.77 \\
\hline $9.6 \pm 0.5$ & $10.2 \pm 1.2$ & $2.6 \pm 0.4$ & \pm 0.9 & $0.8 \pm 0.1$ & $6.9 \pm 0.8$ & $0 \cdot 70$ \\
\hline $13.5 \pm 0.5$ & $10 \cdot 3 \pm 1$ & $2.8 \pm 0.5$ & $5 \cdot 7 \pm 0.6$ & $0.7 \pm 0.05$ & $6.8 \pm 0.6$ & 0.69 \\
\hline
\end{tabular}

* Expressed as a percentage of the total fatty acids.

$\dagger$ Ratio of unsaturated/saturated fatty acids. Cyclopropane fatty acids (17 $\triangle$ and $19 \triangle)$ are counted with the unsaturated fatty acids.

\section{Effects of solvents on fatty acid composition}

These are summarized in Table 3, along with the corresponding measured MIC value. For alcohols, MIC values rapidly decreased as the chain lengths of alcohols increased. Regarding the effects on fatty acid composition, in the case of acetone there was a decrease in 16:1 and an increase in 16:0. Similar results were obtained with ethanol, except that $18: 1$ also increased. A decrease in 16:1 and an increase in 16:0 were also observed in the case of butanol but in addition, $18: 1$ decreased and $14: 0$ increased. With longer-chain alcohols a different pattern was observed as the shorter-chain fatty acids $12: 0$ and 14:0 increased whereas 16:0 remained constant. There was a large decrease in $16: 1$ and a slight increase in $17 \triangle$ and $19 \triangle$. Thus for these alcohols, decreases in the unsaturated/saturated $(\mathrm{U} / \mathrm{S})$ ratio and a shortening of the fatty acid chain length were observed.

\section{Effect of growth temperature on fatty acid composition}

When the fermentation temperature was decreased from 38 to $25^{\circ} \mathrm{C}$, there was an increase in $16: 1$ and a decrease in $18: 1$ as well as of $17 \triangle$ and $19 \triangle$ (Table 4). The U/S ratio remained constant, the main effect being on fatty acid chain length which decreased when temperature decreased, as shown by the variations in the chain-length ratio. 


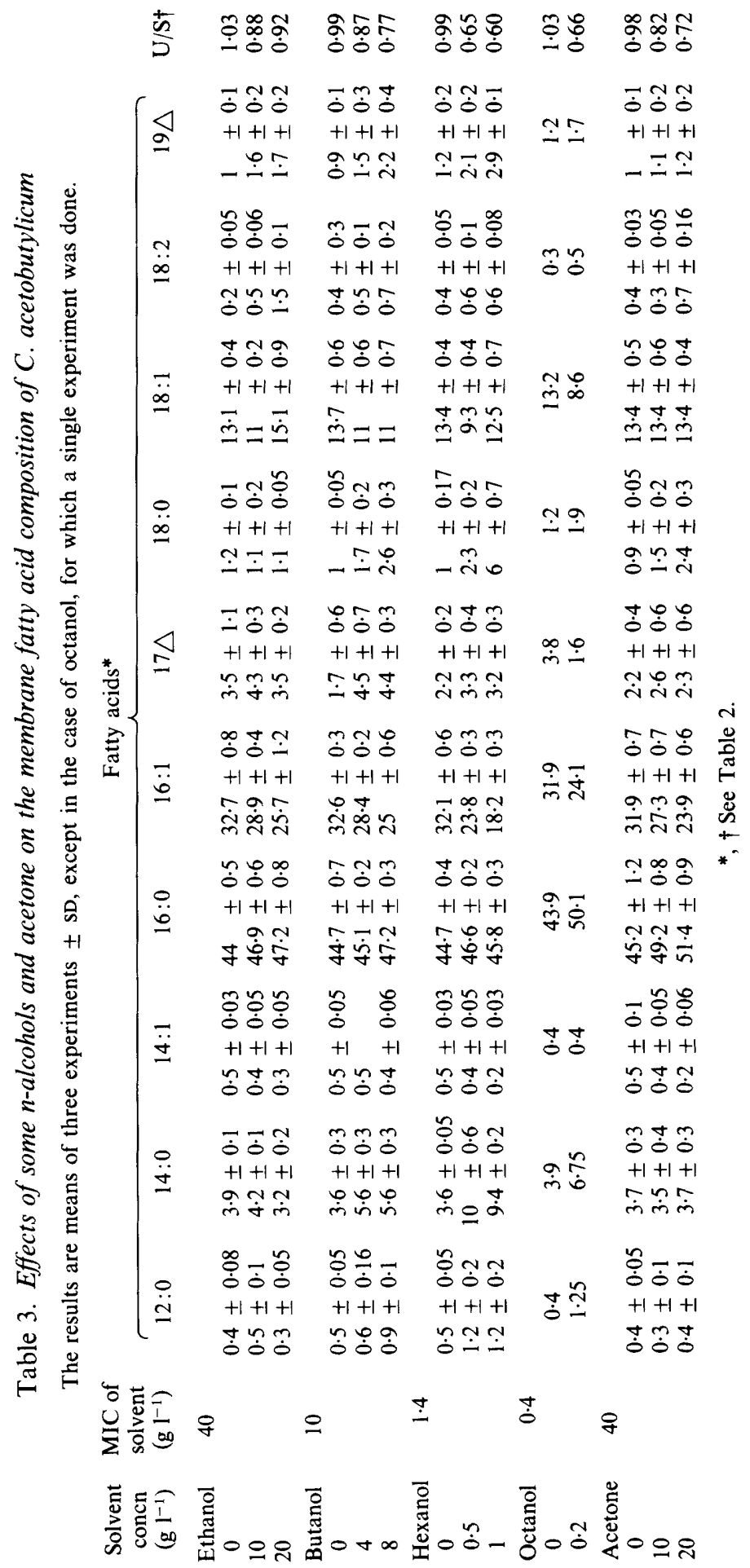




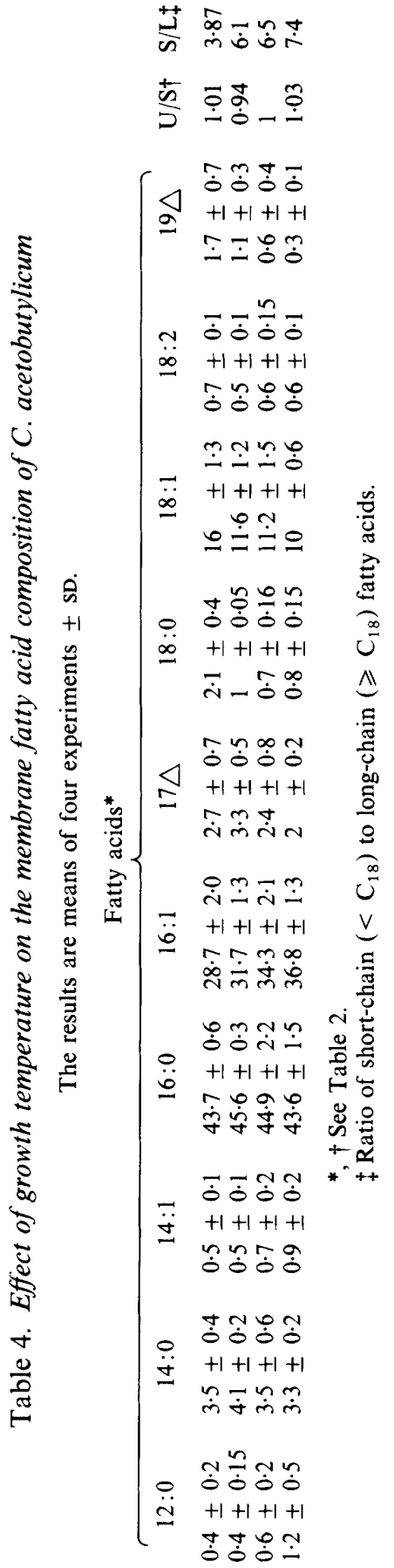

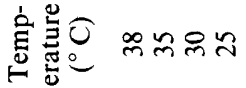

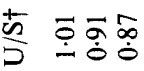

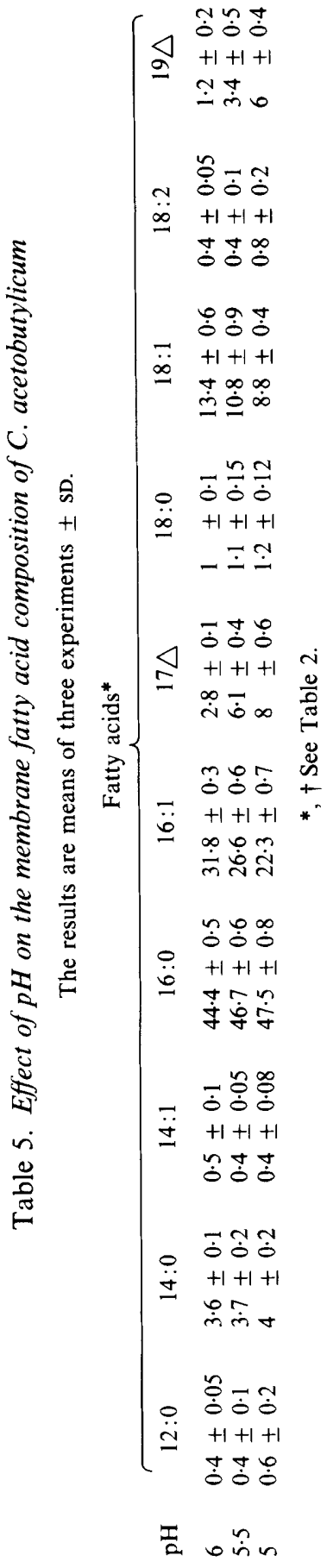




\section{Effect of $\mathrm{pH}$ on fatty acid composition}

The main effects were a decrease in 16:1 and 18:1 and an increase in 17 $\triangle$ and $19 \triangle$ when the $\mathrm{pH}$ was decreased from 6 to 5 (Table 5).

\section{DISCUSSION}

Few studies have been made on the lipid composition of $C$. acetobutylicum (Johnston \& Goldfine, 1983; Vollherbst-Schneck et al., 1984), but more detailed investigations have been made of closely related species such as Clostridium saccharoperbutylacetonicum (Ogata et al., 1982) and Clostridium butyricum (Goldfine \& Bloch, 1961; Baumann et al., 1965; Khuller \& Goldfine, 1974; Johnston \& Goldfine, 1983; Koga \& Goldfine, 1984). Johnston \& Goldfine (1983) reported for C. acetobutylicum ATCC 824 the same fatty acids and alk-1-enyl chains as we observed with strain 903 , except that the $18: 2$ acid was not found. However, the quantitative values for individual fatty acids were quite different from ours. It is likely, as shown by the results of the present study, that culture conditions largely account for these differences. The fatty acid composition of $C$. acetobutylicum ATCC 824 obtained by Vollherbst-Schneck et al. (1984) was also similar to ours except for the absence of the 12:0,17 $\triangle, 19 \triangle$ and $18: 2$ acids which were not mentioned. The presence of the $18: 2$ acid as a minor constituent in our preparations was unexpected since polyunsaturated fatty acids are not known to be synthesized in anaerobic micro-organisms. It is thus probable that this acid, whose identity was confirmed by MS, originated from the culture medium.

The available literature also provides hints as to the nature of phospholipid PX which was detected in our preparations. Ogata et al. (1982), working on C. saccharoperbutylacetonicum, also separated on TLC an unknown phospholipid in conditions quite similar to ours. Johnston \& Goldfine (1983) identified in C. acetobutylicum an unusual phospholipid, previously identified in C. butyricum (Matsumoto et al., 1971), as the glycerol acetal of ethanolamine plasmalogen. The following points lead us to tentatively identify PX with this compound: PX was ninhydrin positive; it did not present a diacyl form in plasmalogen analysis; it migrated exactly as did lyso$\mathrm{PE}$; analysis of fatty acid composition by acidic transesterification showed that PX contains over $30 \%$ of dimethylacetals.

Large changes in lipid composition of $C$. acetobutylicum were brought about by addition of solvents. Alcohols of various chain lengths, and acetone, caused a decrease in the U/S ratio. This effect can be interpreted as an adaptive response to the interactions of solvents with membrane lipids. As insertion of alcohols into the membrane lipid bilayer would tend to increase the fluidity of the membrane, it would be counterbalanced by the opposite effect of the decrease of the U/S ratio (Ingram, 1976). Longer-chain alcohols, however, have also been found to shorten the fatty acid chain lengths and this additional effect cannot be interpreted in general terms of membrane fluidity. A suitable explanation would probably have to take into account the complex structure of the membrane and the possibility of specific interactions of the alcohols with individual lipid components.

The influence of growth temperature on membrane lipid composition has been extensively studied. Since the work of Marr \& Ingraham (1962) with Escherichia coli, much evidence has been accumulated to support the interpretation summarized by Sinensky (1974) in the concept of 'homeoviscous adaptation'. Our results are in line with this interpretation but $C$. acetobutylicum reacts to an increase in temperature mainly by shortening the fatty acid chain length, in a way similar to that described for C. butyricum (Khuller \& Goldfine, 1974). It should also be noted that in $C$. acetobutylicum, an increase in membrane fluidity is brought about in different ways: the presence of solvents decreases the degree of unsaturation whereas a temperature decrease shortens the chain lengths of the fatty acids.

The overall changes in lipid composition brought about during acetone-butanol fermentation were largely accounted for by solvent production. It thus seems puzzling that $C$. acetobutylicum has a lipid composition which is little different from the non-solvent-producing species $C$. butyricum. A possible reason could be that acids such as butyric acid produced by the latter interact with the membrane in a way related to that of solvents. Solvent production, however, cannot account for all the variations in lipid composition observed in $C$. acetobutylicum. The 
presence of cyclopropane fatty acids in particular has been found to be strongly influenced by $\mathrm{pH}$. In addition, these acids appear to be synthesized during acetone-butanol fermentation in a way which, as reported by Rock \& Cronan (1982) for $E$. coli, appears related to changes from the exponential to the stationary phase of growth. Explanations for such changes in fatty acid composition would require some understanding of the specific role of cyclopropane fatty acids in membrane structure.

\section{REFERENCES}

Balch, W. E., Fox, G. E., Magrum, L. J., Woese, C. R. \& WOLPE, R. S. (1979). Methanogens: reevaluation of a unique biological group. Microbiological Reviews 43, 260-296.

Baumann, N. A., Hagen, P. O. \& Goldfine, H. (1965). Phospholipids of Clostridium butyricum. Studies on plasmalogen composition and biosynthesis. Journal of Biological Chemistry 240, 1559-1567.

BLIGH, E. G. \& DYER, W. J. (1959). A rapid method of total lipid extraction and purification. Canadian Journal of Biochemistry and Physiology 37, 911-917.

Folch, J., LeEs, M. \& SloANe-Stanley, G. H. (1957). A simple method for the isolation and purification of total lipids from animal tissues. Journal of Biological Chemistry 226, 497-509.

Gentner, P. R., Bauer, M. \& Dieterich, I. (1981). Separation of major phospholipids classes of milk without previous isolation from total lipid extracts. Journal of Chromatography 206, 200-204.

GoldFINE, H. \& BLOCH, K. (1961). On the origin of unsaturated fatty acids in Clostridia. Journal of Biological Chemistry 236, 2596-2601.

Hermann, M., Fayolle, F., Marchal, R., Podvin, L., Sebald, M. \& Vandecasteele, J. P. (1985). Isolation and characterization of butanol resistant mutants of Clostridium acetobutylicum. Applied and Environmental Microbiology 50, 1238-1243.

Herrero, A. A., Gomez, R. F. \& Roberts, M. F. (1982). Ethanol-induced changes in the membrane lipid composition of Clostridium thermocellum. Biochimica et biophysica acta 693, 195-204.

INGRAM, L. O. (1976). Adaptation of membrane lipids to alcohols. Journal of Bacteriology 125, 670678.

JAIN, M. K. \& WU, N. M. (1977). Effect of small molecules on the dipalmitoyl lecithin liposomal bilayer. III. Phase transition in lipid bilayer. Journal of Membrane Biology 34, 157-201.

Jain, M. K., Gleeson, J., Upreti, A. \& Upreti, G. G. (1978). Intrinsic perturbing ability of alkanols in lipid bilayers. Biochimica et biophysica acta 509, 1-8.

JOHNSTON, N. C. \& GoldFine, H. (1983). Lipid composition in the classification of the butyric acidproducing clostridia. Journal of General Microbiology 129, 1075-1081.

Khuller, G. K. \& Goldfine, H. (1974). Phospholipids of Clostridium butyricum. V. Effects of growth temperature on fatty acid alk-l-enyl ether group, and phospholipid composition. Journal of Lipid Research 15, 500-507.

KoGA, Y. \& Goldfine, H. (1984). Biosynthesis of phospholipids in Clostridium butyricum: kinetics of synthesis of plasmalogens and the glycerol acetal of ethanolamine plasmalogen. Journal of Bacteriology 159, 597-604.

MarR, A. G. \& Ingraham, I. L. (1962). Effect of temperature on the composition of fatty acids in Escherichia coli. Journal of Bacteriology 84, 12601267.

Matsumoto, M., TamiYa, K. \& Kolzumi, K. (1971). Neutral lipids and a new type of aldehydogenic ethanolamine phospholipid in Clostridium butyricum. Journal of Biochemistry 69, 617-620.

Moreira, A. R., Ulmer, A. C. \& Linden, J. C. (1981). Butanol toxicity in the butylic fermentation. Biotechnology and Bioengineering Symposium 11, 567-579.

Morrison, W. R. \& SMiTh, L. M. (1964). Preparation of fatty acids methyl esters and dimethylacetals from lipids with boron fluoride-methanol. Journal of Lipid Research 5, 600-608.

NelsoN, G. J. (1975). Isolation and purification of lipids from animal tissues. In Analysis of Lipids and Lipoproteins, pp. 1-22. Edited by E. G. Perkins. Champaign: American Oil Chemists' Society.

Ogata, S., Vosnino, S., OKuma, Y. \& Hayashida, S. (1982). Chemical composition of autoplast membrane of Clostridium saccharoperbutylacetonicum. Journal of General and Applied Microbiology 28, 293301.

Pelick, N. \& Mahadeyan, V. (1975). Lipids derivates and gas liquid chromatography. In Analysis of Lipids and Lipoproteins, pp. 23-35. Edited by E. G. Perkins. Champaign: American Oil Chemists' Society.

ROCK, C. O. \& CRONAN, J. E., JR (1982). Regulation of bacterial membrane lipid synthesis. Current Topics in Membranes and Transport 17, 207-233.

Rouser, G., Fleischer, S. \& Yamamoto, A. (1970). Two dimensional thin layer chromatographic separation of polar lipids and determination of phospholipids by phosphorus analysis of spots. Lipids $\mathbf{5}$, 494-496.

RuSSELL, N. J. (1984). Mechanisms of thermal adaptation in bacteria: blueprints for survival. Trends in Biochemical Sciences 9, 108-112.

SINENSKY, M. (1974). Homeoviscous adaptation. A homeostatic process that regulates the viscosity of membrane lipids in Escherichia coli. Proceedings of the National Academy of Sciences of the United States of America 71, 522-525.

Viswanathan, C. V., Phillips, F. \& Lundberg, W. O. (1968). Two-dimensional reaction thin-layer chromatography in the analysis of phosphatide plasmalogens. Journal of Chromatography 35, 66-71.

Vollherbst-SchNeCK, K., SAND, J. A. \& MonteneCOURT, B. S. (1984). Effect of butanol on lipid composition and fluidity of Clostridium acetobutylicum ATCC 824. Applied and Environmental Microbiology 47, 193-194.

Walton, V. \& Martin, J. L. (1979). Production of butanol-acetone by fermentation. In Microbial Technology, vol. 1, pp. 187-209. Edited by H. J. Peppler \& D. Perlman. London: Academic Press. 